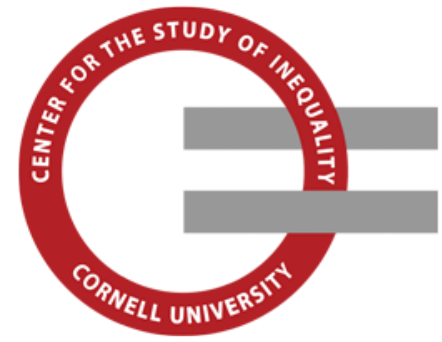

Center for the Study of Inequality Cornell University

363 Uris Hall

Ithaca, NY 14850

(607)254-8674

inequality@cornell.edu

www.inequality.cornell.edu

Feeding the pipeline: Gender, occupational plans, and college major selection

Stephen L. Morgan

Cornell University

Dafna Gelbgiser

Cornell University

Kim A. Weeden

Cornell University

Final version published as: Morgan, Stephen L., Dafna Gelbgiser, and Kim A. Weeden. 2013. "Feeding the pipeline: Gender, occupational plans, and college major selection." Social Science Research 42(4):989-1005. DOI: 10.1016/j.ssresearch.2013.03.008.

Copyright: Following publisher guidelines, this post-print is released with a Creative Commons Attribution Non-Commercial No Derivatives License.

This article is brought to you free and open access by the Center for the Study of Inequality Collection in eCommons@cornell.edu.

Follow this and additional works at: https://ecommons.cornell.edu/handle/1813/52084 


\title{
Feeding the pipeline: Gender, occupational plans, and college major selection
}

\author{
Stephen L. Morgan*, Dafna Gelbgiser, Kim A. Weeden \\ Department of Sociology, Cornell University, Ithaca, New York, United States
}

\section{A R T I C L E I N F O}

\section{Article history:}

Received 9 November 2012

Revised 12 February 2013

Accepted 26 March 2013

Available online $\mathrm{xxxx}$

\section{Keywords:}

Education

College major

Gender

STEM

Occupational plans

\begin{abstract}
A B S T R A C T
In this article, we analyze gender differences in college major selection for respondents to the Education Longitudinal Study (2002-2006), focusing on educational pathways through college that lead to science, engineering, or doctoral-track medicine occupations and to non-doctoral track clinical and health sciences occupations. We show that gender differences in college major selection remain substantial, even for a cohort in which rates of enrollment in postsecondary education are more than ten percent higher for young women than for young men. Consistent with other recent research, we demonstrate that neither gender differences in work-family goals nor in academic preparation explain a substantial portion of these differences. However, the occupational plans of high school seniors are strong predictors of initial college major selection, a finding that is revealed only when occupational plans are measured with sufficient detail, here by using the verbatim responses of students. We also find that the association between occupational plans and college major selection is not attributable to work-family orientation or academic preparation. Finally, we find gender differences in the associations between occupational plans and college major selection that are consistent with prior research on STEM attrition, as well as with the claim that attrition also affects the selection of majors that are gateways into doctoral-track medicine. We discuss the implications of the predictive power of occupational plans formed in adolescence for understanding sex segregation and for policies intended to create a gender-balanced STEM and doctoral-level medical workforce.
\end{abstract}

(c) 2013 Elsevier Inc. All rights reserved.

\section{Introduction}

Between 1940 and 1990, the segregation of occupations by gender in the United States declined sharply, driven in large part by women's entry into the traditionally male-dominated professions (Cotter et al., 2004; Weeden, 2004). After 1990, however, the pace of integration slowed, just as women's college enrollment and completion rates began to outpace men's (see Buchmann and DiPrete, 2006; DiPrete and Buchmann, 2006; Goldin et al., 2006). ${ }^{1}$ To help explain this puzzle, recent scholarship examines trends in the segregation of men and women across college majors and fields of study and finds that the integration of majors also began to slow after the mid-1980s (e.g., England and Li, 2006; Barone, 2011). A related, although largely independent, multidisciplinary literature focuses on women's slow integration in science, engineering, and medical occupations, and likewise shows that women's underrepresentation in science majors in college is a contributing factor (e.g., Xie and Shauman, 2003).

\footnotetext{
* Corresponding author. Address: Department of Sociology, 323 Uris Hall, Cornell University, Ithaca, NY 14853, United States.

E-mail address: morgan@cornell.edu (S.L. Morgan).

1 A related literature that tracks gender differences in fields of study across countries shows remarkable similarities across industrial societies (Bradley, 2000; Charles and Bradley, 2002, 2009; see Buchmann et al., 2008; Gerber and Cheung, 2008 for overviews).
} 
Both literatures imply that a key to understanding the persistence of occupational segregation is to unravel processes occurring much earlier in the life course, processes that lead young women and young men to choose gender-differentiated educational pathways that channel them, albeit imperfectly, into different occupations. In this article, we analyze gender differences in college major selection for respondents to the Education Longitudinal Study ([ELS] 2002-2006). We focus on the educational pathways through college that lead to occupations in science, technology, engineering, mathematics (STEM) and doctoral-level medicine. We also give sustained attention to a persistent gender divide in the propensity to select science majors that lead to clinical and health occupations (e.g., nursing, health technicians). In much of the extant literature on STEM college major selection, medicine is either ignored altogether, thereby missing educational pathways that capture a large proportion of students in science, or all health-related majors are lumped together, thereby conflating educational pathways to occupations that differ in the mix of science and math skill sets they involve, the amount and type of training they entail, their working conditions, their occupational cultures, their economic and social rewards, and the extent to which they are the focus of policy efforts to increase American technological competitiveness. ${ }^{2}$ By dif- $^{-}$ ferentiating STEM and doctoral-level medicine from other clinical and health occupations, we improve on this extant literature. $^{3}$

To connect our analysis to other research on pathways into STEM careers, we assess two commonly posited determinants of gender differences in college major choices: academic preparation in high school and attitudes toward work and family. To foreshadow our results, we show that neither factor accounts for much of the gender difference in initial college major selection. Although these findings are consistent with some extant empirical research on older cohorts of students (e.g., Xie and Shauman, 2003) and on college-to-career transitions (e.g., Sassler et al., n.d.), they fly in the face of much academic theorizing about why women are underrepresented in STEM careers (see, e.g., Ceci et al., 2009; Williams and Ceci, 2012; see also Eccles, 2011a,b), not to mention lay and journalistic accounts of women's underrepresentation in STEM.

Our positive contribution is to introduce an obvious, yet surprisingly neglected, predictor in theoretical and empirical models of college major choices: the occupational plans developed by the end of high school. Our empirical analysis features a novel measure that uses verbatim responses to capture important qualitative differences in students' occupational plans. Our results show a strong association between planning to enter a science, engineering or mathematics occupation or doctoral-level medical occupation and initial college major choice, and, similarly, a strong association between planning to enter a non-doctoral track health or clinical science occupation and college major choice. Critically, we find that these associations cannot be reduced to gender differences in work-family orientation or academic preparation. We also show substantial gender differences in the likelihood of choosing a STEM or doctoral-track medicine major, conditional on occupational plans, which is consistent with the claim that women are more likely to leak from STEM and doctoral-level medicine pipelines.

\subsection{Past models of educational pathways into STEM and medical careers}

Before presenting our results, we briefly review the literatures that have informed prior efforts to understand gender differences in entry into science, engineering, and medicine, as well as the broader literature on college major selection. We then discuss prior efforts to model STEM major selection and make the case for including high school occupational plans in such models.

\subsubsection{Pipeline and life course models}

The dominant metaphor invoked to account for the under-representation of women in science is the "pipeline model," which posits a relatively rigid, straightforward progression through a fixed set of transition points in educational and occupational careers (see Berryman, 1983). The gender composition of the science workforce is a function of initial differences between young women and men in their likelihood of entering "the pipeline," coupled with gender differences in the likelihood of dropping out along the way (see, e.g., Alper, 1993). The literature that attempts to identify the mechanisms behind pipeline leakage from college through early and mid-careers is now vast, ranging from arguments that grant explanatory power to spatial abilities that are partly heritable (e.g., Halpern et al., 2007) to those that grant explanatory power to structures of oppression (e.g., Johnson et al., 2011).

The pipeline literature provides a useful starting point for understanding the gender gap in STEM fields and careers, but it focuses disproportionately on social processes that unfold in college, graduate school, and early careers. These transition

\footnotetext{
${ }^{2}$ Because of their origins in science workforce policy concerns, pipeline models have tended to focus narrowly on travel through acronymical pipes - from the S/E pipeline (for science and engineering), to the SME pipeline (for science, mathematics, and engineering), and now predominantly the STEM pipeline (for science, technology, engineering, and mathematics). Although some studies include medicine as part of a STEMM pipeline (see Miller and Kimmel, 2012), rarely are students sorted into doctoral-level and non-doctoral level medical occupations. We avoid using the STEMM label precisely because we differentiate these two levels of medical occupations, and instead use the more accurate but also more cumbersome, "STEM and doctoral-level medicine."

${ }^{3}$ In the language of contemporary segregation research, segregation across STEM and doctoral-level medical occupations, on one hand, and clinical and health occupations, on the other, has both a vertical and a horizontal dimension. The vertical dimension is typically operationalized with mean occupational income or prestige, and the horizontal with the residual association after fitting all available gradational measures of occupational standing. As shall become clear, it is not possible to impose meaningful gradational scales on either our measure of occupational plans, which captures uncertainty and multiplicity of plans as well as content, or college majors.
} 
points are temporally proximate to career outcomes in the STEM and medical workforce, but equally important decisions and processes occur earlier in the life course. In particular, prevailing explanations for leaky pipelines do not adequately account for gender differences in the selection of the educational pathways, including college major, that tend to lead into science, engineering, medical, and other science-related occupations. ${ }^{4}$

Although not part of the "science pipeline" literature per se, a substantial literature on these earlier life course stages gives clues to the sources of gender differences in the selection of science-related majors. Within this literature, attention typically focuses on two core factors: gender differences in ability and gender differences in preferences. Debate continues over the magnitude of these gender differences and, if they exist, whether they are biologically based, learned through socialization and interactions with family and friends, internalized reflections of widely held cultural beliefs about men and women's competencies, anticipatory responses to work-family conflicts embedded in gendered organizational and institutional structures, or adaptations to perceived opportunity structures. We cannot hope to summarize all of the existing empirical work on these debates, and so we instead highlight the research that is most relevant to STEM, doctoral-track medical, or clinical and health college majors.

To explain women's differential entry into and exit from STEM college majors, many scholars focus on differences between young men and women in the experiences and interactions they have in college with others in their interaction networks. For example, in an ethnographic study of 335 students at seven institutions of higher education, Seymour and Hewitt (1997) show that more young women than men attributed their initial choice of a science, math, or engineering major to the active encouragement of someone important to them. However, female students who entered STEM because of this encouragement were disproportionately likely to leave STEM, largely because of negative experiences with faculty and male peers (see also Seymour, 1995). This stream of literature points to the importance of gender differences in day-to-day interactions while in college on STEM major choice, but it tells us little about gender differences among students who, prior to entering college, may have had science-related occupational goals and hence might be especially receptive to the influence, positive or negative, of those in their interaction networks. ${ }^{5}$

Another set of explanations for gender-differentiated college major selection focuses on students' self-assessed competence at science and math (Ridgeway, 2012; see also Correll, 2001). Catsambis (1994) shows that female middle school and high school students have less interest and confidence in mathematics than young men, even though they exhibit similar levels of performance. Correll (2001) demonstrates that, even after adjusting for performance levels, male high school students rate themselves as more competent than young women. These self-assessment effects can persist throughout college. Cech et al. (2011), in a longitudinal study of engineering students at four institutions, find that although math selfassessment is not associated with persistence in the engineering major, "professional role competence" is, and contributes to gender gaps in attrition from engineering. In each case, the core argument is that widely held cultural beliefs about men and women's competencies affect young men and women's perceptions of their own abilities and suitability for STEM occupations and, as a result, the likelihood of selecting a STEM major (conditional on performance).

Although they do not focus on college major choice per se, a related set of arguments points to gender-differentiated socialization that subjects women and men at all life-stages to ongoing, subtle, and yet powerful pressures to conform to sex-typical career paths and decisions (see, e.g., Jacobs, 1989). Normative expectations about women's status as primary caregivers encourage women to choose career paths that are, or are believed to be, more compatible with raising a family (e.g., the "preference theory" espoused by Hakim (2002)). ${ }^{6}$ In this view, it is not that young women lack confidence in their ability to do science or be scientists, but they gravitate toward other pursuits in response to (a) their preferences for high involvement in child-rearing and other "hands-on" and time-consuming aspects of family life; and (b) the incompatibility - perceived or real - between science and family life.

In a related argument, Ceci et al. (2009) claim that there are genuine gender differences in occupational preferences that reflect some mixture of "free" and "constrained" choices. The latter are best understood as accommodations to beliefs, whether accurate or inaccurate, that some careers are more compatible than others with the biological exigencies of motherhood. The former reflect stable and deep-rooted differences between men and women in their preferences for particular types of tasks, but especially for caring, nurturing, and interacting with people as opposed to objects. Ceci et al. (2009) provide no new evidence in support of this essentialist claim, but their interpretive review identifies "pronounced sex differences in occupational preferences that occur along a 'people-to-object' dimension (Lippa, 1998): Women are more likely to pursue people-oriented or organic fields, whereas men with similar mathematics and science ability tend to pursue object-oriented fields (Webb et al., 2007; see Lippa, 2005, for a review)." The research reported in these citations

\footnotetext{
${ }^{4}$ Not all STEM majors wind up in STEM occupations (see, e.g., Sassler et al., n.d.); and, conversely, some pathways into the science pipeline emerge late in educational careers (Xie and Shauman, 2003). Even so, entrants into many STEM and doctoral-level medicine occupations are disproportionately drawn from the pool of students with a science-related college degree.

5 Brotman and Moore (2008) provide an overview of within-school processes identified in the science education literature that might lead to genderdifferentiated likelihoods of majoring in STEM or persisting with STEM coursework. At the college level, an experimental study by Logel et al. (2009) showed that young women's interactions with men can negatively affect their performance in engineering. Other scholars point to the typical pedagogy of required introductory science courses (e.g., organic chemistry), which may "weed out" a higher proportion of women than men (for a review, see Scantlebury and Baker, 2007). More recently, Moss-Racusin et al. (2012) show through a series of experimental studies that academic scientists evaluate mailed applications (from fictitious high school seniors) for lab manager positions more favorably if they believe the applicant is male.

${ }^{6}$ The elicited preferences in Hakim (2002) are from a sample of women aged 16 to 64 in Britain, the vast majority of whom had made their career choices long before they were surveyed.
} 
is based entirely on convenience samples that, in our view, offer less than persuasive evidence. ${ }^{7}$ Nevertheless, Ceci et al. (2009; see also Williams and Ceci, 2012) exemplify the common argument that gender differences in occupational preferences reflect men and women's stable and deeply ingrained preferences for caring or nurturing, that, when coupled with beliefs about the incompatibility of science with caring or nurturing, make women less likely to choose STEM occupations.

Eccles' (1994; see also Eccles', 2011a,b) expectancy-value model is one of the most influential and comprehensive developmental models of achievement-related choices, and continues to inform research today. In this model, the educational and occupational choices of young women and men are conditioned by feedback received from "socializers." To explain gender differences in STEM persistence, the framework posits that young women develop lower levels of confidence in STEM-related coursework and, through a process of subjective valuation, come to regard STEM-related courses and careers as less interesting, and of less personal value, than other courses or other careers. However, young men and women's subjective task valuations are also affected by their gender-role ideology, and in particular their beliefs about what career options are viable given their relative valuation of family and childrearing (Eccles, 2011a,b). Although the expectancy-value model thus differs from other models of STEM major selection in that it emphasizes gender differences in relative valuations and focuses on developmental processes that begin much earlier in the life course, at a more fundamental level its predictions are quite compatible with the Ceci and colleagues' "free and constrained" choice model and Hakim's preference theory: gender differences in the selection of science majors will be strongly associated with gender differences in work-family valuations. $^{8}$

The STEM-specific and general literatures on college major selection are thus replete with mechanisms that can account for gender differences in the likelihood of selecting a science-related major. By far the most rigorous and empirically informed evaluation of these mechanisms is Xie and Shauman's (2003) Women in Science: Career Choice Processes and Outcomes. Xie and Shauman offer a subtle alternative to the pipeline model that permits a wider range of analysis: a life course perspective that allows "the significant events and transitions in an individual's life [to be] age-dependent, interrelated, and contingent on (but not determined by) earlier experiences and societal forces" (2003:12).

In the portions of their analysis most relevant to our own, Xie and Shauman (2003) show that remarkably little of the gender differences in intended college major or in college major selection among the college-bound high school classes of 1982 and 1992 can be attributed to gender differences in high school coursework, tested performance, future work-family orientation, or self-assessed competence in math. Based on a series of empirical models, they conclude that "none of the[se] explanatory variables has significant power in explaining the sex differences in the likelihood that students who enroll in college chooses to pursue an S/E [science or engineering] major" (Xie and Shauman, 2003:91) ${ }^{9}$ For all the attention lavished on tested performance, coursework, or work-family orientation, gender differences in these variables offer remarkably little leverage to explain gender differences in STEM major selection.

\subsubsection{Occupational plans and college major selection}

In much of the theoretical literature just recounted, gender differences in college major are assumed to reflect, at least in part, gender differences in occupational tastes and preferences. This is true whether gender affects preferences though ability and prior academic preparation, gender-biased self-assessed ability, socialization into gender roles, innate and biologically based preferences, or adaptations to institutional and organizational constraints.

Curiously, empirical models of STEM major selection that include measures of detailed occupational plans are almost non-existent. Xie and Shauman (2003), for example, do not include a measure of students' occupational plans in high school in models of gender differences in college major intentions or in college major selection. This decision is standard in both the literature on STEM major selection and the more general literature on college major selection (e.g., Davies and Guppy, 1997; England and Li, 2006; Goyette and Mullen, 2006; Kimmel et al., 2012; Riegle-Crumb et al., 2012; Turner and Bowen, 1999). ${ }^{10}$ In one of the few exceptions, Legewie and DiPrete (2012) offer an analysis of the NELS data that includes students' early "STEM orientation" measured with two indicators, one of which is a dummy variable from the NELS 8th grade occupational plan

\footnotetext{
7 Lippa (2005) summarizes results from four convenience samples: a 1976 study of twins, the same 1991 Cal-State Fullerton sample analyzed in Lippa (1998), a 2002 internet survey with an unknown sampling design but with 30\% of its respondents from California, and a dual convenience sample of Cal-State Fullerton students and participants in two gay pride festivals, all of whom agreed to participate in a study of finger-length ratios and sexual orientation. The Webb et al. (2007) sample is "precocious youth" who (a) scored at or above the 97th percentile, and in many cases at or above the 99.5th percentile, in math or reading, (b) participated in a voluntary "talent search" program and associated enrichment activities, and (c) survived the longitudinal study's $48 \%$ attrition rate.

${ }^{8}$ Working within this framework, Bleeker and Jacobs (2004) and Jacobs and Bleeker (2004) present results in support of a claim that a mother's belief about her children's science competence affects whether her daughters and sons develop a greater interest in science compared to other pursuits.

9 Among high school seniors in the 1992 NELS, the unadjusted female-to-male odds ratio for intending to complete a science or engineering major is 0.31 ; this odds ratio never increases to more than 0.35 , even after adding up to 47 measures of coursetaking, performance on standardized tests, socioeconomic status, family attitudes, and students' attitudes toward math (see Xie and Shauman, 2003, Table 3.2, p. 67). In their models of gender differences in the likelihood of selecting a science or engineering major, Xie and Shauman (2003) analyze the HSB data, which are based on a sample of high school sophomores in 1980. They show an unadjusted female-to-male odds ratio of selecting a science or engineering major of 0.27 . After specifying similar adjustment variables as their NELS-based analysis and adding a measure of whether or not students intended to major in science or engineering while in high school, they show that the adjusted odds ratio increases to only 0.34 .

10 Economists often include forward-looking labor market expectations in their models of college major choice, but the critical feature of expectations is anticipated earnings, not planned occupation (e.g., Arcidiacono, 2004; Arcidiacono et al., 2012; Montmarquette et al., 2002; Polachek, 1978).
} 
responses for students who selected "science or engineering professional, such as engineer or scientist" instead of one of 12 other possibilities.

In our analysis, we will consider qualitative differences in occupational plans and educational pathways that lead into science-related occupations. Our measure of occupational plans, which we describe in greater detail below, captures whether high school students plan to be scientists, engineers, doctoral-level medical professionals (e.g., doctors, veterinarians), or nurses and health technicians. Similarly, we differentiate college majors into three types: (1) majors in STEM and doctoral-track medicine; (2) majors in health and clinical sciences, such as nursing and rehabilitation; and (3) all other educational pathways to non-STEM and non-medical careers. Our STEM and doctoral-track medicine major category includes students who complete the pre-med prerequisites while formally completing non-STEM majors, on the argument that such students are "in the pipeline" even if they are majoring in liberal arts.

We also ask whether the association between occupational plans and college major selection can be attributed to gender differences in performance, coursework, or work-family orientations measured in high school. If arguments about exogenously determined gender differences in occupational preferences (e.g., Hakim, 2002), "free and constrained" choices (Ceci et al., 2009), or subjective task valuations (Eccles, 2011a,b) are correct, it should be the case that any association between occupational plans and college major selection will disappear, or at least be greatly diminished, in models that include measures of work-family orientation. Thus, although our primary interest is in the consequences of occupational plans rather than their sources, our analyses speak to the theoretical claim that gender differences in occupational preferences emerge, at least in part, from gender differences in work-family preferences.

\subsection{Research questions}

In our empirical analysis, we will answer four questions:

1. In representative samples of high school students, do young women and men have qualitatively different occupational plans that suggest differential interest in occupations in science, mathematics, engineering, doctoral-level medicine, and non-doctoral clinical and health sciences?

2. Do any such differences predict college major decisions that are gateways into (a) occupations in science, mathematics, engineering, and doctoral-level medicine or (b) related but non-doctoral-level occupations in clinical and health sciences?

3. Can any explanatory power of occupational plans be "explained away" by pre-college gender differences in coursework, academic performance, or work-family goals?

4. Are there gender differences in the likelihood of selecting majors that lead into (a) occupations in science, mathematics, engineering, and doctoral-level medicine, or (b) non-doctoral level occupations in clinical and health sciences, conditional on planning in high school to enter these occupations?

\section{Methods}

\subsection{Data and analysis sample}

Our data are drawn from the 2002 base-year, 2004 follow-up, and 2006 follow-up waves of the ELS. The ELS is a nationally representative sample of students in public and private high schools conducted by the U.S. Department of Education, and a close (although not identical) successor to the NELS data analyzed by Xie and Shauman (2003), Legewie and DiPrete (2012), and others. Although the ELS contains a slightly less extensive set of predictors than those available for the HSB and NELS, ${ }^{11}$ the ELS better reflects the college major choices of new entrants into today's labor market, and of a cohort of young men and women who began their secondary schooling well after women became the majority of college attendees. ${ }^{12}$

We analyze the ELS panel sample, which includes 12,591 respondents who participated in all three rounds of the survey. For most of our analysis, we restrict the sample to the 7909 respondents who were enrolled in postsecondary institutions in 2006 and additionally to the 5996 respondents who declared a college major by 2006 .

We weight the data by the base-year and second follow-up panel weight (BYF2WT, developed by the data distributors), multiplied sequentially by two estimated inverse probabilities that account for (a) non-participation in all three waves of the survey and (b) non-response on the dependent variable of the relevant model (when non-response is present). The estimated probabilities for (a) and (b) were drawn from separate logit models that predict inclusion in the relevant restricted sample with demographic characteristics, family background, and base-year indicators of academic engagement. Our models of college major selection among all attendees of postsecondary institutions are thus estimated for the 5996 respondents who were enrolled in a postsecondary institution in 2006 and who reported a college major, but weighted to the full distribution of the 7909 members of the panel sample who were known to be enrolled in a postsecondary institution in 2006. Parts (a)

\footnotetext{
${ }^{11}$ For example, the ELS data lack many of the high-school level predictors used by Legewie and DiPrete (2012) in their analysis of the contextual effect on gendered self-assessments of ability.

${ }_{12}$ We will not formally model the consequences of compositional shifts in college attendance between the NELS and ELS cohorts, although we think this a useful task for future research.
} 
and (b) of the weights have very modest consequences on our results, and all of the primary features of our analysis would be the same in models that are only adjusted by the base-year and second follow-up panel weight (BYF2WT).

\subsection{Variables and modeling strategy}

We will present and explain our measured variables as they are introduced into the analysis. For each variable, item-specific missing data were imputed by the data distributors or by our application of best-subset linear and logistic regression.

\section{Results}

In our models of gender differences in college major selection, we analyze two overlapping groups of students. The first group consists of all students enrolled in any postsecondary educational institutions in 2006. The second group, hereafter "traditional four-year college students," consists of students who (a) enrolled in a 4-year college in the first available enrollment window following high school graduation in 2004, and (b) remained continuously enrolled in a 4-year college through the data collection window in 2006.

\subsection{Gender differences in college major selection}

Table 1 presents the distribution of male and female students across declared college majors for these two groups. In the 2006 interview, respondents were asked "Have you declared a major yet at [your current postsecondary educational institution]?" and then "What is your major field of study?" The verbatim responses to these questions were coded by the data distributors using the 2000 version of the Classification of Instructional Programs (CIP). We categorized these coded responses, after supplementing them with our own coding of the verbatim responses provided with the restricted-access data, into a three-category college major variable. The first category, "STEM or doctoral-track medicine," includes students who (a) reported relevant CIP-coded STEM, pre-med, pre-vet, and pre-dental majors, or (b) reported pre-med, pre-vet, or pre-dental studies in their verbatim responses (regardless of their CIP-coded majors). The second category, "clinical or health sciences (not doctoral-track)," includes students who reported majors with CIP-codes such as nursing, pharmacy, and nutrition and did not indicate pre-med, pre-vet, or pre-dental studies in their verbatim responses. The third category, "other major," includes students who reported CIP-coded majors that were neither STEM nor clinical/health sciences and who did not indicate pre-med, pre-vet, or pre-dental studies in their verbatim responses. ${ }^{13}$

Table 1 shows that young men are more than twice as likely as young women to select STEM or doctoral-track medicine majors, whether one considers all students attending postsecondary institutions (33.1\% versus $13.2 \%$ ) or only traditional 4 year college students (34.3\% versus $15.4 \%$ ). Conversely, young women who are enrolled in any postsecondary institution in 2006 are nearly four times as likely as young men to choose non-doctoral track health and medicine majors (20.4\% versus 5.6\%), and young women who are enrolled in traditional 4-year colleges are three times more likely than young men to choose these majors (15.1\% versus 5.4\%). Finally, and as consequence of the combined differences in science major selection, young women are slightly more likely than young men to declare other majors. This is especially true among traditional 4year college students, where the difference is $9 \%$ points (69.5\% versus $60.3 \%$ ).

Before assessing potential explanations for these differences, we should clarify two analysis decisions that differ from past research on college major selection. First, we include doctoral-level medicine alongside STEM majors in our first category because we are interested in gender-typed occupations for which substantial and often advanced undergraduate science and mathematics courses are required. Existing research on older cohorts suggests that young women are disproportionately likely to favor pathways toward doctoral-level medicine in comparison to those that lead to STEM careers, a pattern we also find for this cohort. ${ }^{14}$ Accordingly, the gender differences in Table 1, which are quite large, would be larger still if our first category was limited to STEM majors. In the final portion of our analysis below, we will demonstrate that our main conclusions are at least as strong when we attempt to separate STEM majors from those who are on the doctoral-track pathway toward medical careers.

Second, as we noted above, our results are weighted by the inverse estimated probability of declaring a college major. The gender differences in Table 1 are thus estimated as if all students had chosen majors by 2006, under the implicit assumption that when the 1913 college students who have not selected majors decide to select majors, they will do so in the same pattern as the 5996 students who have selected majors. This may be an unrealistic assumption, especially if a greater portion of these 1913 students will drop out of postsecondary education before selecting a major. Still, we chose this weighting strategy because it allows us to preserve inferences to a full population of enrolled college students, the population on which other findings are commonly reported. Our decision is unlikely to affect the main patterns of results, because the gender difference in not selecting a college major is small. ${ }^{15}$

\footnotetext{
${ }^{13}$ The mapping of CIP codes, and supplemental verbatim coding, to our three categories is presented in Supplementary Appendix Table S1. Students who listed more than one major were coded as follows: if none of the majors were in science or medicine, students were coded as "other." If at least one major was "STEM or doctoral-track medicine," students were coded as "STEM or doctoral-track medicine" (regardless of the other majors listed). If at least one major was "clinical or health sciences" and but none were doctoral-track medicine, students were coded as "clinical or health sciences (not doctoral-track)."

${ }^{14}$ For details, see Supplementary Appendix Tables S2 and S12.

${ }^{15}$ See Supplementary Appendix Table S3.
} 
Table 1

Declared college major by gender in 2006. Source: Education Longitudinal Study (2002-2006).

\begin{tabular}{|c|c|c|c|c|}
\hline & \multicolumn{2}{|l|}{ Male } & \multicolumn{2}{|c|}{ Female } \\
\hline & $N$ & Percent & $N$ & Percent \\
\hline \multicolumn{5}{|l|}{ All students in postsecondary institutions } \\
\hline \multicolumn{5}{|l|}{ Major } \\
\hline STEM or doctoral-track medicine & 887 & 33.09 & 433 & 13.17 \\
\hline Clinical or health sciences (not doctoral-track) & 149 & 5.55 & 671 & 20.42 \\
\hline Other major & 1644 & 61.35 & 2182 & 66.41 \\
\hline Total & 2680 & 100.00 & 3286 & 100.00 \\
\hline \multicolumn{5}{|c|}{ Traditional 4-year college students (immediate entry in 2004 into a 4-year college and continuous enrollment through 2006) } \\
\hline \multicolumn{5}{|c|}{ Major } \\
\hline STEM or doctoral-track medicine & 647 & 34.32 & 362 & 15.43 \\
\hline Clinical or health sciences (not doctoral-track) & 101 & 5.35 & 353 & 15.06 \\
\hline Other major & 1137 & 60.33 & 1631 & 69.51 \\
\hline Total & 1884 & 100.00 & 2347 & 100.00 \\
\hline
\end{tabular}

Notes: $N=5966$ for panel a, and $N=4231$ for panel b. Data are weighted. See the Supplementary Appendix for a full explanation of the college major categories and the main text for an explanation of the weights.

\subsection{Gender differences in observed predictors of major field of study selection}

Can the established explanations for gender differences in fields of study account for these gender differences in college major selection? We next introduce the three core sets of predictors for our analysis, separately by gender: (1) work-family goals, (2) coursework and academic performance in high school, and (3) occupational plans prior to college entry.

\subsubsection{Work-family goals}

Table 2 presents our measures of respondents' goals for family and work, which replicates the "family vs. work attitude scale" proposed and used by Xie and Shauman (2003) for the NELS data. As high school seniors, all ELS respondents were asked to rate 18 separate items in response to the question, "How important is each of the following to you in your life?" The response distributions to the four items used by Xie and Shauman are presented in Table 2 for male and female students enrolled in any postsecondary institution in 2006. ${ }^{16}$

Gender differences on these indicators are very small for "finding the right person to marry and having a happy life" as well as "being successful in your line of work." Gender differences are larger for "having children," with almost 10\% more of female high school seniors indicating that having children was very important rather than somewhat important to them. Gender differences are largest for the importance of "having lots of money," with nearly 14\% more of male high school seniors indicating that this goal was very important rather than somewhat important to them.

The final row of Table 2 reports the scale formulated by Xie and Shauman (2003) but using the ELS data: the sum of the two items on work goals subtracted from the sum of the two items on family goals. As one would anticipate from the distributions on the underlying items, the gender difference in favoring family life goals over work life goals is modest at 0.26 . ${ }^{17}$ No more than 5-7\% of male students are more inclined to favor work goals over family goals, generating gender differences of no more than $10-14 \%$.

\subsubsection{Gender differences in coursework and academic performance in high school}

The first two panels of Table 3 present, for all students enrolled in postsecondary education, gender differences in prior high school math and science coursework. Our measure of prior coursework follows the NCES high school transcript coding scheme developed by Burkham and Lee (2003). Among the nearly 95\% of the ELS respondents in our sample who had complete official transcript data coded by the data distributors, $5 \%$ more young men than women took advanced math to the calculus level (21.7\% versus $16.7 \%){ }^{18}$ The gender gap in levels of advanced science coursetaking is similar.

The third panel of Table 3 shows that these modest differences in coursetaking patterns are reflected in results on standardized math tests administered for the ELS. Among college-bound high school sophomores and seniors, young men score slightly higher on standardized math tests than young women. There is no comparable gender difference in reading test scores in the sophomore year (the 2004 ELS, when most respondents were seniors, did not include a reading test). College-bound young women have higher average cumulative grade point averages by the end of high school than collegebound young men.

\footnotetext{
16 Supplementary Appendix Table S4 presents similar results for the traditional 4-year college students.

17 The scale difference reported by Xie and Shauman (2003:252) was .32 for NELS students who expected to attend college. A decline in this difference from .32 to .26 between 1992 and 2002 fits our expectations, but there are differences in the sampling designs of the NELS and ELS that prevent a direct comparison.

18 These gaps were slightly larger for traditional 4-year college students, as shown in Supplementary Appendix Table S5.
} 
Table 2

Goals for work and family by gender in 2004 for all students in postsecondary institutions in 2006. Source: Educational Longitudinal Survey (2002-2006).

\begin{tabular}{lrr}
\hline & Male & Female \\
\hline Importance of marrying right person/having happy family (\%) & & 2.65 \\
Not important & 3.07 & 13.21 \\
Somewhat important & 14.95 & 84.56 \\
Very important & 82.44 & 0.57 \\
Missing & 0.53 & 100.00 \\
Total & 100.00 & \\
Importance of having children (\%) & & 13.28 \\
Not important & 12.82 & 30.69 \\
Somewhat important & 41.20 & 55.21 \\
Very important & 45.45 & 0.81 \\
Missing & 0.53 & 100.00 \\
Total & 100.00 & \\
Importance of being successful in line of work (\%) & & 0.05 \\
Not important & & 5.58 \\
Somewhat important & 0.48 & 94.03 \\
Very important & 6.58 & 0.35 \\
Missing & 92.63 & 100.00 \\
Total & 0.30 & \\
Importance of having lots of money (\%) & 100.00 & 11.76 \\
Not important & & 63.47 \\
Somewhat important & & 24.42 \\
Very important & 9.28 & 0.35 \\
Missing & 52.20 & 0.165 \\
Cotal & 38.07 & 0.46 \\
\hline
\end{tabular}

Notes: $N=5966$. Data are weighted. The standard deviation for the family-work values composite variable is 1.178 for men and 1.200 for women. The composite measure was created based on Xie and Shauman construction of FamilyWork values composite measure (2003, p. 281, note \#14). The first two variables were added to a scale of importance of family (2-6 scale), and the latter two were added to a scale of importance of work (2-6 scale). The composite measure is the result of the importance of family scale-importance of work scale.

\subsubsection{Gender differences in occupational plans prior to college entry}

Our measure of occupational plans is based on a question in the 2004 ELS self-administered student questionnaire that instructed respondents to "Write in the job or occupation that you expect or plan to have at age 30." Students could write in a response, select "you don't know," or skip the question. ${ }^{19}$ The data processors contracted by the Department of Education coded verbatim responses to this prompt into 17 occupation categories including "professional a", "professional b," "school teacher," "protective service," "other," and categories consistent with census major occupation groups. These categories do not enable any specific modeling of science-related occupational plans, because most occupations in STEM and medicine are embedded in "professional a" and "professional b."20

Fortunately, the data distributors also provided the verbatim responses to the occupational plans question as metadata available to approved users of the restricted-access ELS data. We assembled our own team to code these verbatim responses, using 1220 distinct categories for occupations based on, but a more detailed version of, the codes developed for the 2000 Standard Occupational Classification (SOC) of the Bureau of Labor Statistics. We then grouped these 1220 categories into a variable tailored to capture differences in occupational plans that, according to the literature, should predict selection into STEM or doctoral-track medicine majors or non-doctoral level clinical and health sciences majors.

Table 4 presents gender differences in the categories of occupational plans from the two overlapping samples of students (see also Table 1). The "STEM only" category includes students who only listed a STEM occupation or, less frequently, STEM occupations. The most common occupations were computer programmers, mechanical engineers, and computer hardware

\footnotetext{
19 According to the 2004 questionnaire, respondents had a fourth choice, "Not planning to work at age 30." The raw dataset indicated that no students selected this response. However, the same question in 2002 (sophomore year) elicited "Not planning to work" responses from $0.8 \%$ of the sample. We suspect, based on examination of the coding of the seventeen-category variable F10CC30, that 99 respondents in 2004 actually chose "Not planning to work at age 30 " but were coded by the data distributors as "item legitimate skip/NA."

${ }^{20}$ The data distributors summarize the "professional a" category as "PROFESSIONAL such as accountant, artist, registered nurse, engineer, librarian, writer, social worker, actor, actress, athlete, politician, but not including school teacher" and the "professional b" category as "PROFESSIONAL such as clergy, dentist, physician, lawyer, scientist, college teacher" (NCES Base-Year to First Follow-up Data File Documentation, Appendix G, page G-240, NCES 2006-334).
} 
Table 3

High school math and science coursework and academic performance by gender for all students in postsecondary institutions in 2006. Source: Educational Longitudinal Survey (2002-2006).

\begin{tabular}{lrr}
\hline & Male & Female \\
\hline Math coursework pipeline level (\%) & & \\
Below middle academic ii & 12.14 & 11.51 \\
Middle academic ii & 21.42 & 23.35 \\
Advanced i & 17.41 & 20.20 \\
Advanced ii (pre-calculus) & 21.61 & 22.95 \\
Advanced iii (calculus) & 21.66 & 16.68 \\
Missing transcripts & 5.76 & 5.32 \\
Total & 100.00 & 100.00 \\
& & \\
Science coursework pipeline level (\%) & & 18.22 \\
Low-level science & 19.96 \\
Chemistry 1 or physics 1 & 29.79 & 36.38 \\
Chemistry 1 and physics 1 & 22.47 & 19.41 \\
Chemistry 2 or physics 2 (and/or other advanced) & 8.96 \\
Chemistry 2 and physics 2 (and/or other advanced) & 13.06 & 12.16 \\
Missing transcripts & 5.76 & 8.51 \\
Total & 100.00 & 5.32 \\
& & 100.00 \\
Academic performance (mean) & & \\
2002 math test score & 49.78 & \\
2002 reading test score & 32.97 & 46.24 \\
2004 math test score & 55.96 & 33.06 \\
2004 cumulative grade point average & 2.93 & 51.73 \\
\hline
\end{tabular}

Notes: $N=5966$. Data are weighted. The coursework pipeline measures are based on the NCES transcript coding scheme proposed by Burkam and Lee (2003). For men, the standard deviations for the performance variables are $13.51,9.21,14.27$, and 0.75 . For women, the standard deviations for the performance variables are $12.67,8.72,13.40$, and 0.70 .

Table 4

Occupational plans by gender in 2004. Source: Educational Longitudinal Survey (2002-2006).

\begin{tabular}{lrr}
\hline & Male & Female \\
\hline All students in postsecondary institutions & & \\
Occupational plans (\%) & & \\
STEM only & 17.86 & 4.28 \\
Medicine (doctoral level) & 5.95 & 8.24 \\
Biological, health, or clinical sciences (master's level and lower) & 4.64 & 17.50 \\
Medicine (doctoral level) and another occupation of any type & 0.47 & 1.05 \\
Non-STEM, non-Medicine, and non-biological/health/clinical sciences & 40.97 & 43.48 \\
Other mixture without doctoral-level medicine & 1.18 & 0.85 \\
Don't know & 26.29 & 22.85 \\
Missing & 2.65 & 1.75 \\
Total & 100.00 & 100.00 \\
& & \\
Traditional 4-year college students & & \\
Occupational plans (\%) & & \\
STEM only & 20.73 & 4.83 \\
Medicine (doctoral level) & 6.61 & 9.21 \\
Biological, health, or clinical sciences (master's level and lower) & 4.79 & 15.50 \\
Medicine (doctoral level) and another occupation of any type & 0.29 \\
Non-STEM, non-Medicine, and non-biological/health/clinical sciences & 38.94 & 4.00 \\
Other mixture without doctoral-level medicine & 1.24 & 0.92 \\
Don't know & 25.35 & 22.76 \\
Missing & 2.04 & 1.02 \\
Total & 100.00 & 100.00 \\
\hline
\end{tabular}

Notes: $N=5966$ for panel a, and $N=4231$ for panel b. Data are weighted. See the Supplementary Appendix for a full explanation of the occupational plans categories and the main text for the explanation of the weights.

engineers, but all of the customary math and science occupations (e.g., physicists, chemists, and mathematicians) are represented. Table 4 shows that male high school students were more than four times as likely as female students to have listed only STEM occupations in their plans, whether the sample includes all students who later enrolled in postsecondary institutions ( $17.9 \%$ versus $4.3 \%$ ) or only 4 -year college-bound students ( $20.7 \%$ versus $4.8 \%$ ). 
We coded occupations in medicine and biology into three categories differentiated by the level of education typically required and the mix of jobs offered. The first category, "medicine (doctoral-level)," includes students who listed only jobs that we coded as requiring a doctoral degree, such as physicians, surgeons, veterinarians, and dentists. The second category, "biological, health, or clinical sciences (master's level and lower)" includes students who listed only jobs that typically require less than a doctoral degree, such as registered nurses, therapists, nutritionists, pharmacists, physicians assistants, and dental hygienists. The third category, "medicine (doctoral level) and another occupation of any type," includes those who listed more than one occupational plan, at least one of which was in doctoral-level medicine.

Table 4 shows that female high school seniors were more likely to have occupational plans in each of these three categories, contrary to the pattern for STEM occupational plans. Young women were 1.4 times more likely than young men to plan to enter doctoral-level medical occupations: $8.2 \%$ versus 6.0\% (all students bound for any postsecondary institution) and $9.2 \%$ versus $6.6 \%$ (students bound for traditional 4 -year colleges). The gender difference in aspirations to enter biological, health, and clinical science occupations at the master's level and lower was as large as, albeit in the opposite direction of, the gender difference in STEM occupational plans. Among all future postsecondary students, 17.5\% of young women aspired to master's level biological, health, and clinical science occupations, compared to $4.6 \%$ of young men; among students who later entered traditional 4-year colleges, the difference was smaller but still substantial at $15.5 \%$ of young women and $4.8 \%$ of your men. For the small but mixed category of doctoral-level medicine and any other planned occupation, a similar, although imprecisely estimated gender difference, was also evident. Here, the most common combinations were pairs of occupations such as "doctor" and "pharmacist," which we interpret as an indication of uncertainty about one's future trajectory.

Finally, college-bound male high school seniors were slightly more likely than their female counterparts to offer a response of "don't know" to the occupational plans question: $26.3 \%$ versus $22.9 \%$ among all future postsecondary students, and $25.4 \%$ versus $22.8 \%$ among students who would later enroll in traditional 4-year colleges. Young men were also slightly more likely than young women to decline to answer the question (2.7\% versus $1.8 \%$ and $2.0 \%$ versus $1.0 \%$ for the two overlapping samples).

The gender differences reported in Tables 1-4 suggest that occupational plans will be the strongest predictor, among the variables just presented, of gender differences in college major selection. Of course, predictive power rests not only on gender differences in the predictors, but also on the power of the predictors to account for major selection. We next turn to models that directly assess predictive power.

\subsection{Multinomial logit models of gender differences in college major selection}

Table 5 presents coefficients, in log odds form, for multinomial logit models where the dependent variable is the threecategory college major selection variable presented in Table 1. The reference category in each model is "other major," and the coefficients reported in the columns of the table represent log odds differences of selecting majors in our other two categories relative to this category.

\subsubsection{A multinomial logit model of unadjusted gender differences}

Model 1, which includes as its sole predictor a dummy variable for female students, is a multinomial logit representation of the gender differences in college major selection patterns that we reported in Table 1 . As in Table 1 , Table 5 shows that women in any postsecondary institution are much less likely to select a STEM or doctoral-track medicine major than men, and much more likely to select a non-doctoral track clinical or health sciences major, with logit coefficients of -1.00 and 1.22, respectively (Model 1, Panel A). The corresponding coefficients estimated for students in traditional 4-year colleges are -.94 and .89 , respectively (Model 1, Panel B). These coefficients, all of which are high multiples of their standard errors, suggest that the large substantive differences reported in Table 1 are highly statistically significant by conventional standards.

\subsubsection{A baseline model with adjustments for family background}

Model 2 adds to Model 1 basic demographic and family background characteristics of students, including three indicator variables for self-identified race, three indicator variables for region of residence, two indicator variables for urbanicity (defined by location of the school), three indicator variables for family structure, and five dimensions of socioeconomic status (mother's education, father's education, mother's occupational prestige, father's occupational prestige, and family income). These additional variables are collectively predictive, as suggested by the increases in the model Chi-squared test statistics. However, their inclusion has little effect on the logit coefficients for gender, which change by no more than 0.03 points for coefficients with standard errors of 0.08 or more. Accordingly, there appear to be no interactive effects of demographic and socio-economic status characteristics (or, by implication, their unmeasured linear correlates) with gender in the process of college major selection. One might have wondered, for example, whether the greater likelihood of young women entering clinical or health science majors is partly a consequence of lower-SES female high schools students choosing to enroll in college in greater numbers than lower-SES male high school students. The results are consistent with this claim, but to a degree that is so small that we doubt its substantive import.

Their trivial effects on the gender coefficients notwithstanding, family background variables are standard predictors of college major selection in the literature, and we will therefore refer to Model 2 as our baseline model. Among all students enrolled in postsecondary education in 2006, the coefficient for STEM or doctoral-track medicine from this model is -1.00, 
Coefficients from multinomial logit models for college major selection. Source: Educational Longitudinal Survey (2002-2006).

\begin{tabular}{|c|c|c|c|c|c|c|}
\hline & \multicolumn{2}{|c|}{ Model 1 (unadjusted differences) } & \multicolumn{2}{|c|}{ Model 2 (baseline model) } & \multicolumn{2}{|c|}{ Model 3 (full model) } \\
\hline & $\begin{array}{l}\text { STEM or } \\
\text { doctoral-track } \\
\text { medicine }\end{array}$ & $\begin{array}{l}\text { Clinical or health } \\
\text { sciences (not } \\
\text { doctoral-track) }\end{array}$ & $\begin{array}{l}\text { STEM or } \\
\text { doctoral-track } \\
\text { medicine }\end{array}$ & $\begin{array}{l}\text { Clinical or health } \\
\text { sciences (not } \\
\text { doctoral-track) }\end{array}$ & $\begin{array}{l}\text { STEM or } \\
\text { doctoral-track } \\
\text { medicine }\end{array}$ & $\begin{array}{l}\text { Clinical or health } \\
\text { sciences (not } \\
\text { doctoral-track) }\end{array}$ \\
\hline \multicolumn{7}{|c|}{ All students in postsecondary institutions } \\
\hline Female student & $\begin{array}{l}-1.00 \\
(.08)\end{array}$ & $\begin{array}{l}1.22 \\
(.11)\end{array}$ & $\begin{array}{l}-1.00 \\
(.08)\end{array}$ & $\begin{array}{l}1.19 \\
(.11)\end{array}$ & $\begin{array}{l}-0.92 \\
(.10)\end{array}$ & $\begin{array}{l}0.72 \\
(.13)\end{array}$ \\
\hline \multicolumn{7}{|l|}{$\begin{array}{l}\text { Additional } \\
\text { predictors }\end{array}$} \\
\hline $\begin{array}{l}\text { Family } \\
\text { background }\end{array}$ & & & Yes & Yes & Yes & Yes \\
\hline $\begin{array}{l}\text { Work-family } \\
\text { goals }\end{array}$ & & & & & Yes & Yes \\
\hline $\begin{array}{l}\text { Coursework and } \\
\text { performance }\end{array}$ & & & & & Yes & Yes \\
\hline $\begin{array}{l}\text { Occupational } \\
\text { plans }\end{array}$ & & & & & Yes & Yes \\
\hline Model Chi-square & $\begin{array}{c}334 \\
(2 \mathrm{df})\end{array}$ & & $\begin{array}{c}494 \\
(34 \mathrm{df})\end{array}$ & & $\begin{array}{l}2238 \\
(76 \mathrm{df})\end{array}$ & \\
\hline$N$ & 5966 & & 5966 & & 5966 & \\
\hline \multicolumn{7}{|c|}{ Traditional 4-year college students } \\
\hline Female student & $\begin{array}{l}-0.94 \\
(.10)\end{array}$ & $\begin{array}{l}0.89 \\
(.14)\end{array}$ & $\begin{array}{l}-0.95 \\
(.10)\end{array}$ & $\begin{array}{l}0.87 \\
(.14)\end{array}$ & $\begin{array}{l}-.86 \\
(.12)\end{array}$ & $\begin{array}{l}.32 \\
(.17)\end{array}$ \\
\hline \multicolumn{7}{|l|}{$\begin{array}{l}\text { Additional } \\
\text { predictors: }\end{array}$} \\
\hline $\begin{array}{l}\text { Family } \\
\text { background }\end{array}$ & & & Yes & Yes & Yes & Yes \\
\hline $\begin{array}{l}\text { Work-family } \\
\text { goals }\end{array}$ & & & & & Yes & Yes \\
\hline $\begin{array}{l}\text { Coursework and } \\
\text { performance }\end{array}$ & & & & & Yes & Yes \\
\hline $\begin{array}{l}\text { Occupational } \\
\text { plans }\end{array}$ & & & & & Yes & Yes \\
\hline Model Chi-square & $\begin{array}{l}171 \\
(2 \mathrm{df})\end{array}$ & & $\begin{array}{c}288 \\
(34 \mathrm{df})\end{array}$ & & $\begin{array}{c}1579 \\
(76 \mathrm{df})\end{array}$ & \\
\hline$N$ & 4231 & & 4231 & & 4231 & \\
\hline
\end{tabular}

Notes: Data are weighted. Robust standard errors in parentheses.

which corresponds to a baseline gender gap for STEM and doctoral-level medicine majors of $19.9 \%$ (given predicted values of 0.132 for young women and 0.331 among young men). For traditional 4 -year college students, the corresponding coefficient is -0.95 , or a gap of $18.9 \%$ with predicted values of 0.154 and 0.343 for young women and men, respectively. For non-doctoral-track clinical and health sciences, the gender gaps are in the opposite direction, with coefficients of 1.19 and .87 indicating gender differences of $14.9 \%$ for all postsecondary students (with predicted probabilities of 0.204 and 0.056 for young women and young men) and 9.7\% for 4-year college students only (with predicted probabilities of 0.151 and 0.054 ).

\subsubsection{A full model with adjustments for goals, coursework, performance, and plans}

Model 3 adds 21 predictors to the baseline Model 2: the work-family goals scale (see Table 2), indicator variables for levels of math and science coursework and for academic performance (see Table 3), and indicator variables for occupational plans (see Table 4). ${ }^{21}$

Considering first the selection of STEM or doctoral-track medicine majors, the inclusion of these variables generates only a modest decline in the multinomial logit coefficients for female students, from -1.00 to -0.92 (all postsecondary students) and from -0.95 to -0.86 (4-year college students). The predicted values associated with these coefficients correspond to gender gaps of $14.3 \%$ and $11.7 \%$, compared to the $19.9 \%$ and $18.9 \%$ gaps estimated in Model 2 . For clinical or health sciences majors, the coefficients decline more substantially under the full model, from 1.19 to 0.72 (all postsecondary students) and from 0.87 to 0.32 (4-year college students). The associated gender gaps of $14.9 \%$ and $9.7 \%$ in Model 2 are reduced to $8.3 \%$ and $4.1 \%$, respectively. At most, then, the additional predictors in the full model account for less than half, and in some cases much less than half, of the gender gaps estimated by our baseline model.

One important finding can now be stated, and it matches past results identified by research that uses less extensive predictors or data from older cohorts: very little of the gender differences in the selection of college majors can be accounted for by characteristics of students measured before they enter college (see also Xie and Shauman, 2003). Our results are thus

\footnotetext{
$\overline{{ }^{21} \text { Supplementary Appendix Table S8 presents the full set of coefficients for both versions of Model } 3 .}$
} 
consistent with the claims in the pipeline-inspired literature that many young women who enter college with an interest in science (or, in our case, plans to enter science occupations) confront cultures and have interactions in college that discourage them from persisting in STEM and encourage them to enter other fields of study.

\subsubsection{The relative predictive importance of goals, coursework, performance, and plans}

That being said, the high-school predictors account for a nontrivial portion of the observed gender differences in college major selection, as indicated not only by the decline in the estimated gender coefficients but also the increase in model Chisquared test statistics (see Table 5). The full multinomial logit model presented as Model 3 does not, however, indicate which of the three sets of predictors - work-family goals, high school coursework and performance, or occupational plans - is the most powerful predictor of the gender gaps.

Does the broader literature on how adolescents plan their educational and occupational futures suggest a temporal ordering of these three sets of variables that can guide model specification? Consider the following lines of argument:

- A family life course planning perspective suggests that students first select work-family goals. They then form occupational plans, select courses of instruction in high school, and commit effort to schooling in ways that are consistent with their work-family goals.

- An occupational interest perspective suggests that students first select occupational plans. These plans then imply a series of work-life goals based on beliefs about their selected occupational trajectory and compel consistent course enrollments and patterns of effort in high school.

- A status socialization perspective suggests that significant others (parents, teachers, and peers) form educational expectations for students after observing their inherent abilities and demonstrated academic performance. Students then select levels of educational and occupational aspirations in response to their signification others, and these aspirations guide motivational decisions that structure course enrollments and effort in high school.

These alternative perspectives on trajectories through the educational system are all plausible, and indeed are reflected in the literature on STEM college major choice (see, e.g., Eccles, 2011a,b). We assume, therefore, that these perspectives have differential validity and likely operate in blended form across latent classes of students that cannot be identified with observed data.

The implication of this assumption is that multinomial logit models cannot be estimated in "echelon" form based on assumptions of temporal order. Accordingly, we offer a more flexible analysis of relative predictive power, which allows us to avoid assumptions about temporal order and still convey what is the clear pattern in the data: occupational plans are far more powerful predictors of college major than work-life goals, prior coursework, or academic performance in high school.

Table 6 summarizes the relative power of the three sets of variables to predict college major choice. The columns labeled "minimum" present the changes in the estimated gender gaps that result from removing the set of variables indicated in each row from the full model, i.e., from Model 3 (see Table 5). The columns labeled "maximum" present the analogous changes in the gender gaps that result from adding the same set of variables to the baseline model (Model 2 in Table 5). To make the changes comparable across the columns, we rescale them as percentages by dividing the absolute value of the change in the gap by the relevant baseline gender gap estimated by Model 2.

For example, when occupational plans are added to the baseline Model 2 (fit to data for 4-year college students), the estimated gender gap for STEM or doctoral-track medicine declines from a baseline of 0.187 to 0.126 . This change is scaled as $32.6 \%$ of the baseline gender gap $[(0.187-0.126) / 0.187=0.326]$. When occupational plans are removed from Model 3, the estimated gender gap in STEM or doctoral-gap medicine increases from 0.118 to 0.161 . This change is scaled as $22.9 \%$ $[-1 *(.118-.161) / .187=.229]$. The range of the baseline gender gap explained by occupational plans thus extends from a minimum of $22.9 \%$ to a maximum of $32.6 \%$, with the difference reflecting alternative choices that analysts could make about the temporal order of the formation of occupational plans, work-family goals, coursework, and performance in high school.

Looking across the cells of Table 6, the pattern is clear. ${ }^{22}$ Even in comparisons that are the most unfavorable to occupational plans (i.e., comparing the minima of the predictive power of occupational plans to the maxima of the predictive power of the other two sets of variables), occupational plans explain at least 1.8 times as much of the gender gaps in college major as high school coursework and performance, and at least 11.1 times as much as work-family goals. The differences in predictive power are considerably larger in maximum-to-maximum comparisons and in minimum-to-minimum comparisons, and they are also especially large in accounting for gender gaps in clinical and health sciences majors. Among these three groups of variables, occupational plans are uniformly the strongest predictors of gender gaps in college major selection.

\footnotetext{
22 Models that adjust only for work-family goals show greater gaps for clinical or health science majors, as indicated by the negative signs on the percentage change measures in Table 6, than other models. This situation arises because the gender difference in work-family goals is reversed in the comparison of clinical and health sciences majors to "other majors." Overall, however, the associations are quite small, with corresponding coefficients well below their standard errors. These flipped signs and small coefficients line up well with our general interpretation that work-family goals, as measured this way, are substantively unimportant predictors of college major decisions.
} 
Relative predictive power in reducing gender gaps in college major selection for variables measuring work-family goals, high school coursework and performance, and occupational plans. Source: Educational Longitudinal Survey (2002-2006).

\begin{tabular}{|c|c|c|c|c|}
\hline & \multicolumn{4}{|c|}{ Percentage changes in gender gaps in college major selection } \\
\hline & \multicolumn{2}{|c|}{ STEM or doctoral-track medicine } & \multicolumn{2}{|c|}{ Clinical or health sciences (not doctoral-track) } \\
\hline & $\begin{array}{l}\text { Minimum (subtracted from } \\
\text { the full model) (\%) }\end{array}$ & $\begin{array}{l}\text { Maximum (added to the } \\
\text { baseline model) (\%) }\end{array}$ & $\begin{array}{l}\text { Minimum (subtracted from } \\
\text { the full model) (\%) }\end{array}$ & $\begin{array}{l}\text { Maximum (added to the } \\
\text { baseline model) (\%) }\end{array}$ \\
\hline \multicolumn{5}{|c|}{ All students in postsecondary institutions } \\
\hline Work-family goals & 0.4 & 1.6 & -0.3 & -0.1 \\
\hline $\begin{array}{c}\text { Coursework and } \\
\text { performance }\end{array}$ & 4.7 & 9.2 & 3.6 & 4.4 \\
\hline Occupational plans & 17.8 & 23.3 & 39.3 & 40.5 \\
\hline \multicolumn{5}{|c|}{ Traditional 4-year college students } \\
\hline Work-family goals & 0.1 & 1.1 & -0.9 & -1.1 \\
\hline $\begin{array}{c}\text { Coursework and } \\
\text { performance }\end{array}$ & 4.6 & 13.0 & 7.1 & 10.3 \\
\hline Occupational plans & 22.9 & 32.6 & 47.5 & 51.4 \\
\hline
\end{tabular}

Notes: $N=5966$ for panel a, and $N=4231$ for panel b.

\subsection{Gender differences in the associations between plans and college major selection}

The results presented so far are not inconsistent with pipeline-inspired models of college major selection, in that even the full model (see Table 5, Model 3) leaves large portions of the gender gaps unexplained. To unpack this result further, Table 7 presents a cross-classification of occupational plans by declared college majors. We present this cross-classification separately by gender, for all students enrolled in postsecondary institutions. ${ }^{23}$

Although many gender differences are present in this two-way association, two are clear and important. Among young men who plan to enter "STEM only" careers, 67.4\% declare a STEM or doctoral-track medicine major. For young women, the corresponding percentage is only $53.9 \%$, with $3.6 \%$ instead choosing non-doctoral track clinical or health sciences majors and $42.4 \%$ choosing a non-science major. Similarly, for young men who plan to enter doctoral-level medical careers, $63.9 \%$ declare a STEM or doctoral-track medicine major, with $9.2 \%$ instead choosing non-doctoral clinical or health majors and $30.0 \%$ choosing a non-science major. For young women who plan to enter doctoral-level medical careers, by contrast, the corresponding percentage selecting a STEM or doctoral-track medicine major is only $46.4 \%$, with $26.7 \%$ choosing non-doctoral-track clinical or health science majors and a roughly equal percentage choosing non-science majors. ${ }^{24}$

The multinomial logit models presented and summarized in Tables 5 and 6 assume that the associations between occupational plans and college major selection do not vary by gender, a position that is at odds with the results just presented in Table 7. If we relax this constraint by estimating models that allow the occupational plans associations to be weaker for young women and then calculating suitable marginal predictive probabilities, our results change only slightly. The same is true when we allow all three groups of variables to have associations with college major selection that vary by gender. In fact, the support for our main conclusion - that occupational plans are a relatively powerful and underappreciated predictor of college major selection patterns - is slightly stronger in models where gender-invariance constraints on coefficients are relaxed. ${ }^{25}$

The main implication of the results in Table 7, we argue, is that even in this very recent cohort, a larger proportion of young women in the ELS are leaving educational pathways to STEM and doctoral-track medical occupations than young men. This result is consistent with the pipeline metaphor, and with many of the mechanisms underlying women's greater attrition posited in the pipeline literature.

\subsection{Sensitivity of results to the college major classification}

For the college major classification analyzed so far, we have included in our first category those respondents who are STEM majors as well as those whom we have identified as doctoral-track medicine students. We have explained that this coding decision is primarily based on our interest in separating traditional gender-typed science and medical occupations for which substantial undergraduate science and mathematics courses are required in college from those in the clinical and health sciences. There is, however, one additional reason for favoring this coding decision: it is very difficult to separate students who are in science majors, and hence in the STEM category, into those who are and those who are not pursuing pre-med, pre-vet, and pre-dental courses of study. For example, it is likely that some biology, biochemistry, and chemistry majors are fulfilling pre-med requirements and will attend medical schools.

\footnotetext{
23 Supplementary Appendix Table S9 gives similar results, for only traditional 4-year college students.

24 We also ran similar models on data for only those students who plan a STEM or doctoral medical occupation. Consistent with our other results, these models confirm that gender differences in college major selection cannot be attributed to attitudes toward work-family balance or prior academic performance in high school.

${ }^{25}$ For results, see Supplementary Appendix Tables S10 and S11.
} 


\section{Table 7}

Occupational plans in 2004 by declared college major in 2006, separately for all male and female students in postsecondary institutions. Source: Educational Longitudinal Survey (2002-2006).

\begin{tabular}{|c|c|c|c|}
\hline & \multicolumn{3}{|l|}{ College major in 2006} \\
\hline & $\begin{array}{l}\text { STEM or doctoral-track } \\
\text { medicine }\end{array}$ & $\begin{array}{l}\text { Clinical or health sciences (not doctoral- } \\
\text { track) }\end{array}$ & $\begin{array}{l}\text { Other } \\
\text { major }\end{array}$ \\
\hline \multicolumn{4}{|l|}{ Male students } \\
\hline \multicolumn{4}{|l|}{ Occupational plans in 2004 (percentage by row) } \\
\hline STEM only & 67.38 & 2.58 & 30.04 \\
\hline Medicine (doctoral level) & 63.89 & 9.19 & 26.92 \\
\hline $\begin{array}{l}\text { Biological, health, or clinical sciences (master's level and } \\
\text { lower) }\end{array}$ & 18.74 & 42.63 & 38.63 \\
\hline $\begin{array}{l}\text { Medicine (doctoral level) and another occupation of any } \\
\text { type }\end{array}$ & 17.46 & 48.95 & 33.59 \\
\hline $\begin{array}{l}\text { Non-STEM, non-Medicine, and non-biological/health/ } \\
\text { clinical sciences }\end{array}$ & 18.49 & 2.03 & 79.48 \\
\hline Other mixture without doctoral-level medicine & 32.83 & 8.22 & 58.95 \\
\hline Don't know & 28.14 & 5.16 & 66.69 \\
\hline Missing & 35.76 & 1.91 & 62.33 \\
\hline Total & 33.09 & 5.55 & 61.35 \\
\hline \multicolumn{4}{|l|}{ Female students } \\
\hline \multicolumn{4}{|l|}{ Occupational plans in 2004 (percentage by row) } \\
\hline STEM only & 53.90 & 3.64 & 42.46 \\
\hline Medicine (doctoral level) & 46.43 & 26.65 & 26.92 \\
\hline $\begin{array}{l}\text { Biological, health, or clinical sciences (master's level and } \\
\text { lower) }\end{array}$ & 12.51 & 62.23 & 25.26 \\
\hline $\begin{array}{l}\text { Medicine (doctoral level) and another occupation of any } \\
\text { type }\end{array}$ & 18.28 & 46.39 & 35.33 \\
\hline $\begin{array}{l}\text { Non-STEM, non-Medicine, and non-biological/health/ } \\
\text { clinical sciences }\end{array}$ & 4.30 & 5.80 & 89.89 \\
\hline Other mixture without doctoral-level medicine & 29.46 & 19.74 & 50.80 \\
\hline Don't know & 9.94 & 15.94 & 74.11 \\
\hline Missing & 14.87 & 20.45 & 64.68 \\
\hline Total & 13.17 & 20.42 & 66.41 \\
\hline
\end{tabular}

Notes: $N=5966$. Data are weighted.

In this final section, we assess the sensitivity of our main conclusion - that occupational plans are comparatively strong predictors of college major selection - to our decision to combine STEM and doctoral-track medicine majors. As noted above, existing research suggests that young women are increasingly likely to favor pathways toward doctoral-level medicine in comparison to those that lead to STEM careers (see Riegle-Crumb et al., 2012). How would our main results change if we separated our "STEM or doctoral-track medicine" category in an attempt to capture this evolving gender differential?

To answer this question, we created a new, four-category variable for college major that splits the "STEM and doctoraltrack medicine" category used in our main models into (1) biological science and pre-med, pre-vet, or pre-dental students (based either CIP codes or their verbatim responses); and (2) a more narrowly defined STEM category. We then re-estimated our main results using this four-category variable. We found that occupational plans continued to be the strongest predictor of college major decisions, and by about the same margin. A similar pattern of implied pipeline leakage was present as well. ${ }^{26}$

\section{Conclusion}

In this article, we have analyzed gender differences in initial college major selection for ELS respondents, focusing on traditional gender-typed educational pathways through college that lead to science, mathematics, engineering, and doctorallevel medicine occupations, or to clinical and health sciences occupations. We have shown that gender differences in work-life attitudes and in high school coursework and academic performance explain only small portions of the gender gap in the choice of a science major, ranging from $2 \%$ to $15 \%$. Work-life attitudes, in particular, show but a very weak relationship to the gender gap in major choice. These results are consistent with the recent work of Mann and DiPrete (2012), Riegle-Crumb et al. (2012) and Perez-Felkner et al. (2012) who have analyzed the same data but with different measurement and modeling strategies. They nonetheless are inconsistent with gender essentialist accounts that point to women's decisions to choose motherhood over science (Williams and Ceci, 2012; see also Hakim, 2002; Ceci et al., 2009) or with expectancy-value models that emphasize the importance of gender role ideologies in the development of subjective valuations of science relative to family (e.g., Eccles, 2011a,b).

\footnotetext{
${ }^{26}$ For details, see Supplementary Appendix Tables S12-15.
} 
We have also presented the novel result that the occupational plans of high school seniors are strong predictors of initial college major selection. The important caveat, however, is that the coding of occupational plans must capture qualitative and substantively important differences in these plans: in the context of a study focused on STEM, this means capturing distinctions between occupational plans to enter science and engineering occupations, doctoral-track medical occupations, nondoctoral track medical occupations, and combinations of occupations that could express uncertainty. Occupational plans can explain no less than $17 \%$ of the gender differences in college major selection and as much as $52 \%$ of them, with the smaller percentages obtaining only if one assumes that occupational plans are determined by work-family goals, coursework, and academic performance in high school. These results are again inconsistent with strong-form preference theories.

Even though our results are inconsistent with much popular theorizing about the sources of gendered "leaks" from the science pipeline, they are not inconsistent with the "leaky pipeline" metaphor itself. Our measured variables leave large portions of the gender gaps in college major unexplained, giving room for the mechanisms identified in the higher education STEM literature to enter with full force after young women and men enroll in postsecondary education. We also show that the occupational plans of young women are less predictive of initial college major selection than the occupational plans of young men. Notably, we find that it is not merely that young women are disproportionately leaving science, but also that larger proportions of young women who, as seniors in high school, show interest in entering science, engineering, math, and doctoral-track medical occupations are eschewing or abandoning majors that lead to these occupations in favor of science-related majors that are gateways to non-doctoral track clinical and health sciences occupations.

These results leave open the possibility that the mechanisms identified in the pipeline literature disrupt the educational and occupational plans of young women more than young men. It could very well be, for example, that young women who enter college with plans to enter educational pathways leading into engineering or doctoral medicine are more likely to experience negative interactions with significant others than young men (see Seymour and Hewitt, 1997), or are more likely to internalize cultural beliefs about men and women's differential competence at more complex science-related tasks (see Correll, 2001).

What are the implications of our results for policies intended to plug leaks in the science pipeline and ensure that talented young women are just as likely as talented young men to enter the scientific workforce? The first lesson is that by the time young men and women enroll in colleges and universities, gender-differentiated occupational plans have not only already been formed, but also have begun to channel young men and young women who have interests and abilities in science into different educational pathways. Although much of the pipeline literature and related policy efforts focus on proximate transitions to, and within, science careers, our results suggest that much earlier interventions are warranted.

Our results also call for greater attention to gender-differentiated processes early in the college career that lead to the attrition of women who, at one time, had aspirations to enter science, engineering, or doctoral-track medical careers, but who wind up in majors that are gateways to non-doctoral-track health and clinical science occupations. These students are not "lost" to science task-niches, but they are lost to the workforce of concern to those who fret about American scientific competitiveness. Additional research, and likely additional data, will be necessary to identify the mechanisms underlying this aspirational leveling and how to mitigate it, but our research at least pinpoints a critical point at which interventions might be most effective.

Our results also inform sex segregation scholarship, especially scholarship that seeks to understand why women continue to be underrepresented in occupations that are, on average, relatively well paid, high prestige, high autonomy, stable, and entail pleasant working conditions. In the broader sex segregation literature, it was for many years unfashionable to explicitly model occupational plans of adolescents, whether because of the intellectual dominance of demand-side explanations (e.g., discrimination, gender-biased organizational practices) or the more pragmatic assumption that the occupational plans of adolescents bear very little relationship to the occupations they will hold as adults and hence are largely irrelevant to understanding the structure of segregation in the labor market. The recent attention devoted to segregation in college major choice represents a step toward acknowledging the processes that generate a gender-differentiated "supply" of workers, and that interact with demand-side processes. Our results imply that scholars also need to look yet earlier in the life course, to understand how gender differentiated occupational plans are formed and evolve, how these plans affect educational decisions, and how, ultimately, they affect the mix of skills and credentials that women and men bring to the labor market.

\section{Acknowledgments}

We thank Thomas Barnes, Shenell Bourne, Elissa Cohen, Theodore Leenman, Catherine Pimentel, Amanda Pinto, William Tannanbaum, and Jennifer Todd for their research assistance. This research was supported by the National Science Foundation (SBES-1023798) and by a Visiting Fellowship for Morgan at Collegio Carlo Alberto. Opinions reflect those of the authors and do not necessarily reflect those of the granting agencies. We thank Sigal Alon and Catherine Riegle-Crumb, as well as the reviewers and Editor, for their helpful comments on prior drafts of this article.

\section{Appendix A. Supplementary material}

Supplementary data associated with this article can be found, in the online version, at http://dx.doi.org/10.1016/ j.ssresearch.2013.03.008. 


\section{References}

Alper, Joe, 1993. The pipeline is leaking women all the way along. Science 260, 409-411.

Arcidiacono, Peter, 2004. Ability sorting and the returns to college major. Journal of Econometrics 121, 343-375.

Arcidiacono, Peter, Joseph Hotz, V., Kang, Songman, 2012. Modeling college major choices using elicited measures of expectations and counterfactuals. Journal of Econometrics 166, 3-16.

Barone, Carlo, 2011. Some things never change: gender segregation in higher education across eight nations and three decades. Sociology of Education 84, $157-176$.

Berryman, Sue E., 1983. Who Will Do Science? Minority and Female Attainment of Science and Mathematics Degrees. Rockefeller Foundation, New York.

Bleeker, Martha M., Jacobs, Janis E., 2004. Achievement in math and science: do mothers' beliefs matter 12 years later? Journal of Educational Psychology 96, 97-109.

Bradley, Karen, 2000. The incorporation of women into higher education: paradoxical outcomes? Sociology of Education 73 , 1-18.

Brotman, Jennie S., Moore, Felicia M., 2008. Girls and science: a review of four themes in the science education literature. Journal of Research in Science Teaching 45, 971-1002.

Buchmann, Claudia, DiPrete, Thomas A., 2006. The growing female advantage in college completion: the role of family background and academic achievement. American Sociological Review 71, 515-541.

Buchmann, Claudia, DiPrete, Thomas A., McDaniel, Anne, 2008. Gender inequalities in education. Annual Review of Sociology $34,319-337$.

Burkham, David T., Lee, Valerie E., 2003. Mathematics, Foreign Language, and Science Coursetaking and the NELS:88 Transcript Data (NCES 2003-01). National Center for Education Statistics, Washington, DC.

Catsambis, Sophia, 1994. The path to math: gender and racial-ethnic differences in mathematics participation from middle school to high school. Sociology of Education 67, 199-215.

Cech, Erin, Rubineau, Brian, Silbey, Susan, Seron, Caroll, 2011. Professional role confidence and gendered persistence in engineering. American Sociological Review 76, 641-666

Ceci, Stephen J., Williams, Wendy M., Barnett, Susan M., 2009. Women's underrepresentation in science: sociocultural and biological considerations. Psychological Bulletin 135, 218-261.

Charles, Maria, Bradley, Karen, 2002. Equal but separate? A cross-national study of sex segregation in higher education. American Sociological Review 67, 573-599.

Charles, Maria, Bradley, Karen, 2009. Indulging our gendered selves? Sex segregation by field of study in 44 countries. American Journal of Sociology 114 , 924-976.

Correll, Shelley J., 2001. Gender and the career choice process: the role of biased self-assessments. American Journal of Sociology 106, 1691-1730.

Cotter, David A., Hermsen, Joan M., Vanneman, Reeve, 2004. Gender Inequality at Work. A volume in the series, The American People: Census 2000. Russell Sage Foundation and Population Reference Bureau, New York, NY.

Davies, Scott, Guppy, Neil, 1997. Fields of study, college selectivity, and student inequalities in higher education. Social Forces 75, $1417-1438$.

Diprete, Thomas A., Buchmann, Claudia, 2006. Gender-specific trends in the value of education and the emerging gender gap in college completion. Demography 43, 1-24.

Eccles, Jacquelynne S., 1994. Understanding women's educational and occupational choices. Psychology of Women Quarterly $18,585-609$.

Eccles, Jacquelynne S., 2011a. Understanding women's achievement choices. Psychology of Women Quarterly 35, 510-516.

Eccles, Jacquelynne S., 2011b. Gendered educational and occupational choices: applying the Eccles et al. model of achievement-related choices. International Journal of Behavioral Development 35, 195-201.

England, Paula, Li, Su, 2006. Desegregation stalled. Gender \& Society 20, 657-677.

Gerber, Theodore P., Cheung, Sin Yi, 2008. Horizontal stratification in postsecondary education: forms, explanations, and implications. Annual Review of Sociology 34, 299-318.

Goldin, Claudia, Katz, Lawrence F., Kuziemko, Ilyana, 2006. The homecoming of American college women: the reversal of the college gender gap. The Journal of Economic Perspectives 20, 133-156.

Goyette, Kimberly A., Mullen, Ann L., 2006. Who studies the arts and sciences? Social background and the choice and consequences of undergraduate field of study. The Journal of Higher Education 77, 497-538.

Hakim, Catherine, 2002. Lifestyle preferences as determinants of women's differentiated labor market careers. Work and Occupations 29, 428-459.

Halpern, Diane F., Benbow, Camilla P., Geary, David C., Gur, Ruben C., Hyde, Janet Shibley, Gernsbacher, Morton Ann, 2007. The science of sex differences in science and mathematics. Psychological Science in the Public Interest 8, 1-51.

Jacobs, Jerry A., 1989. Revolving Doors: Sex Segregation and Women's Careers. Stanford University Press, Stanford, Calif..

Jacobs, Janis E., Bleeker, Martha M., 2004. Girls' and boys' developing interests in math and science: do parents matter? New Directions for Child and Adolescent Development 2004, 5-21.

Johnson, Angela, Brown, Jaweer, Carlone, Heidi, Cuevas, Azita K., 2011. Authoring identity amidst the treacherous terrain of science: a multiracial feminist examination of the journeys of three women of color in science. Journal of Research in Science Teaching 48, 339-366.

Kimmel, Linda G., Miller, Jon D., Eccles, Jacquelynne S., 2012. Do the paths to STEMM professions differ by gender? Peabody Journal of Education 87, $92-113$.

Legewie, Joscha, Diprete, Thomas A., 2012. High School Environments, STEM Orientations, and the Gender Gap in Science and Engineering. Working Paper Series, Social Science Research Network.

Lippa, Richard, 1998. Gender-related individual differences and the structure of vocational interests: the importance of the people-things dimension. Journal of Personality and Social Psychology 74, 996-1009.

Lippa, Richard A., 2005. Subdomains of gender-related occupational interests: do they form a cohesive bipolar M-F dimension? Journal of Personality 73, $693-730$.

Logel, Christine, Walton, Gregory M., Spencer, Steven J., Iserman, Emma C., von Hippel, William, Bell, Amy E., 2009. Interacting with sexist men triggers social identity threat among female engineers. Journal of Personality and Social Psychology 96, 1089-1103.

Mann, Allison, Diprete, Thomas A., 2012. Trends in Gender Segregation in the Choice of Science and Engineering Majors. Working Paper Series, Social Science Research Network.

Miller, Jon D., Kimmel, Linda G., 2012. Pathways to a STEMM profession. Peabody Journal of Education 87, 26-45.

Montmarquette, Claude, Cannings, Kathy, Mahseredjian, Sophie, 2002. How do young people choose college majors? Economics of Education Review 21, 543-556.

Moss-Racusin, Corinne A., Dovidio, John F., Brescoll, Victoria L., Graham, Mark J., Handelsman, Jo, 2012. Science faculty's subtle gender biases favor male students. Proceedings of the National Academy of Sciences of the United States of America 109, 16474-16479.

Perez-Felkner, Lara, McDonald, Sarah-Kathryn, Schneider, Barbara, Grogan, Erin, 2012. Female and male adolescents' subjective orientations to mathematics and the influence of those orientations on postsecondary majors. Developmental Psychology, 25.

Polachek, Solomon William, 1978. Sex differences in college major. Industrial and Labor Relations Review 31, $498-508$.

Riegle-Crumb, Catherine, King, Barbara, Grodsky, Eric, Muller, Chandra, 2012. The more things change, the more they stay the same? Prior achievement fails to explain gender inequality in entry into stem college majors over time. American Educational Research Journal.

Sassler, Sharon, Levitte, Yael, Glass, Jennifer, Michelmore, Katherine, N.d. The Missing Women in STEM? Accounting for Gender Differences in Entrance into STEM Occupations. Working Paper, Cornell University.

Scantlebury, Kathryn, Baker, Dale, 2007. Gender issues in science education research: remembering where the difference lies. In: Abell, Sandra K., Lederman, Norman G. (Eds.), Handbook of Research on Science Education. Lawrence Erlbaum, Mahwah, NJ, pp. $257-286$. 
Seymour, Elaine, 1995. The loss of women from science, mathematics, and engineering undergraduate majors: an explanatory account. Science Education 79, 437-473.

Seymour, Elaine, Hewitt, Nancy M., 1997. Talking about Leaving: Why Undergraduates Leave the Sciences. Westview Press, Boulder, Colo.

Turner, Sarah E., Bowen, William G., 1999. Choice of major: the changing (unchanging) gender gap. Industrial and Labor Relations Review 52, $289-313$.

Webb, Rose Mary, Lubinski, David, Benbow, Camilla Persson, 2007. Spatial ability: a neglected dimension in talent searches for intellectually precocious youth. Journal of Educational Psychology 99, 397-420.

Weeden, Kim A., 2004. Profiles of change: sex segregation in the United States, 1910-2000. In: Maria, Charles, Grusky, David B. (Eds.), Occupational Ghettos: The Worldwide Segregation of Men and Women. Stanford University Press, Palo Alto, CA, pp. 131-178.

Williams, Wendy M., Ceci, Stephen J., 2012. When scientists choose motherhood. American Scientist 100, 138-146.

Xie, Yu, Shauman, Kimberlee A., 2003. Women in Science: Career Processes and Outcomes. Harvard University Press, Cambridge.

\footnotetext{
${ }^{26}$ For details, see Supplementary Appendix Tables S12-15.
} 